the difference between primary and secondary necrosis of the iris.

Dr. George Young, of Colchester, was to have given the next paper but was unfortunately taken ill. Mr. Philip Adams, the Deputy Master, kindly filled the hiatus by reading an interesting paper on three cases of toxic amblyopia, due respectively to iodoform, digitalin, and chlorodyne.

Dr. H. T. Holland, C.I.E., of Quetta, then read a very instructive paper on "Iritis as a post-operative complication of cataract extraction," being a review of 2,627 consecutive extractions for cataract, of which the large majority had been intracapsular, and showed that a higher proportion of iritis took place in those operations which were performed with capsulotomy.

This concluded the proceedings; the attendance of 112 constituted a record in the history of the Congress.

C. Russ Wood.

\title{
MEETING OF THE BRITISH MEDICAL ASSOCIATION, MANCHESTER, JULY 24 and 25, 1929
}

\section{Section of Ophthalmology}

After a short introductory address by Mr. Gray ClegG, the President of the Section, Mr. MacCallan introduced a discussion on "Toxic absorption due to focal septic lesions and its effect on the production of eye diseases." He detailed the various sites of the septic foci, the more common being dental apical abscesses and septic infections of the tonsils, especially in children. Less commonly, intestinal sepsis, chronic appendicitis and sepsis of the pelvic organs in women. The various ocular diseases which were attributed to these causes were corneal ulcer, episcleritis, conjunctivitis, chalazion, iridocyclitis, phlyctenular conjunctivitis, dacryocystitis, retinal hyperaemia, vitreous opacities, primary glaucoma, cataract and progressive myopia.

Dr. ARTHUR HURST said that the mouth should be considered as a whole and in the examination of the teeth all those that were dead should be regarded as possible sources of infection and, even in edentulous patients, buried septic roots should be searched for and extracted if found. He agreed that the tonsils and paranasal sinuses were a frequent source of infection, but did not think that duodenal ulceration was to be regarded as a cause. In Dr. Hurst's experience achlorhydria was a common cause of septic infection due to the loss of bactericidal power of the gastric juice. $\mathrm{Mr}$. 
Musgrave Woodman stated that in his opinion the upper nasal sinuses were a frequent source of infection, not only in ocular but also in cerebral conditions. The technique of washing out the upper ethmoidal sinuses together with that of the sphenoid was described, and the results obtained under this form of treatment; the difficulties which were encountered when these areas were irrigated was dwelt upon. Dr. Arnold Renshaw considered remote, as opposed to direct infection, was very frequently a cause of inflammatory ocular conditions. These could be divided into four groups : (1) Infection during a septicaemia. (2) Embolism in chronic sepsis. (3) Reaction to toxin, elaborated in another region, and (4) degenerative changes due to abnormal enzyme action. Dr. ERNEST MADDOX confined his remarks to dental infection and pointed out the close relation between the teeth and the eyes; but warned his hearers that because dental sepsis was present it was not necessarily, though very frequently, the cause of the ocular condition. He quoted some cases of detached retina which had been relieved by dental extraction. It was pointed out that in children the upper and exposed parts of the teeth were generally infected, and in these patients the superficial parts of the eye, such as the cornea, etc., were attacked, whereas in adults the deeper parts of the teeth, such as the roots, were diseased and similarly the deeper parts of the eye were affected. Mr. INGLIs Pollock emphasized the danger of unirrupted infected teeth which were a cause of ocular disease. He did not think retrobulbar neuritis was frequently due to paranasal sinusitis and rarely found operation on the nose necessary in these cases. Dr. P. Watson Williams drew attention to many cases of paranasal sinusitis which caused ocular disease, and differentiated between a bacterial and toxin infection. The attempts of tissue defence were described and the advantages of eliminating the primary focus dwelt upon. Dr. E. J. Primrose described syphilitic ocular infections which were combined with septic infection and other general conditions and said that treatment should be carried out for each condition. $\mathrm{Mr}$. ORMOND discussed the septic causes of detached retina and suggested a chemical origin of the disease. He asked the opener if he had found septic foci in the teeth in the case of dendritic ulcers of the cornea. Mr. LEASK quoted fourteen cases of orbital cellulitis due to para-nasal sinusitis. Mr. T. Aubrey Jones thought that these ocular diseases were merely symptoms and had treated these cases on the lines advised by Mr. Macdonagh. Mr. Graves mentioned infections of the pituitary body due to sepsis and their treatment by nonspecific protein therapy, such as T.A.B. vaccine, and pointed out that residual abscesses in the antrum were not infrequent causes of these conditions. Mr. Bishop HARMAN discussed the question of septic ocular conditions due to a dental cause, in children, and 
showed the position in the cornea in the lower and inner part where the condition begins when due to dental infection.

On Thursday, July 25, Mr. W. H. KIEP described a modification of Lagrange's operation which consisted of a thickened flap of conjunctiva dissected down to the corneo-scleral margin with a small furrow made near it, a keratome being used for the incision into the anterior chamber and a small portion of the lower lip of the wound being then excised. This is followed by a small peripheral iridectomy and finally the conjunctiva is sutured. The advantages claimed were simplicity and less liability to late infection. Mr. INGLIS Pollock supported the previous speaker as regards the advantages of the Lagrange operation, suggesting the chances of the conjunctival fistula closing in these cases were remote and the end-results better. He preferred the use of the Graefe knife rather than the keratome. Mr. BerNard Cridland thought the Lagrange operation was the best in chronic glaucoma and advised waiting to operate until the tension was reduced to about $40 \mathrm{~mm}$. In his experience, late infection was extremely rare in these cases. $\mathrm{Mr}$. MacCallan discussed the question of late infection and thought it was often due to focal sepsis. Mr. McNabB quoted a case of late infection in Elliot's operation. Mr. ERNEST MADDOX asked if the opener of the discussion had experienced any difficulty in excising the scleral tissue. He described two modifications of Lagrange's operation. Mr. Nell also supported the view of the advantages of Lagrange's operation. Mr. GRAY ClEGG had seen very few infections after Elliot's operation and thought the chances of healing of the sclerotic fistula were greater in Lagrange's operation. Mr. KIEP in reply said he did not agree with the preliminary posterior sclerotomy but always advised injections of hypertonic saline as he had found them more efficacious.

Mr. Bernard CRIDland read a paper on "Minor injuries to the eye in industry," and pointed out that there had been a steady increase of these cases during the last twenty years. The various occupations which caused these injuries and their varieties were described. He showed that protective measures were not used in 70 per cent. of the cases. The loss of time to the workmen was estimated, and shown to be on an average that for every three injuries one day's loss to the workman was incurred. He dwelt upon the economic importance of these factors. Protective measures were fully described and various forms of goggles were shown to the meeting. Mr. Bishop Harman commented on the large number of these minor accidents and said the type of goggles used was not ideal in many respects. Mr. Aubrey Jones mentioned the number of accidents taking place in coal mines and pottery districts' and considered that the employers were not very enthusiastic with regard to the use of protective measures for the 
workers, and further mentioned the large amount of time lost with regard to these cases. Mr. TUDOR Jones discussed the question of wearing glasses in coal mines. Mr. BICKERTON stated he thought the Insurance Companies should be approached as regards the premiums paid in those cases where protectors were in use.

Mr. T. L. DE COURCY read a paper on "The significance of vitreous opacities." He described the development of the vitreous and demonstrated its structure in the adult. The formation of opacities was due to the condition of the blood vessels, the state of the blood, and vestigial remains. It was shown that, in a series of cases, 37 per cent. had vitreous opacities, and the method of examination was described. The causation of asteroid bodies was discussed, also their treatment.

Mr. JAMESON Evans read a paper on "Blindness in old age." The provisions of the Blind Persons Act were criticized and it was shown that the number of these cases was rapidly increasing. The various causes of blindness in old persons were described and it was shown that the chief one was cataract. Mr. Bishop Harman discussed the cause of blindness in old people and stated that his figures showed that the largest number was due to macular degeneration. He thought it would be unwise to have a hard and fast rule as regards the definition of blindness. Mr. ClEGG asked if it was obligatory for a blind patient with cataract to have it operated upon.

\section{ABSTRACTS}

\section{I.-TUMOURS}

(1) Treacher Collins, E.-Diseases of the retina. Notes on the natural history of retinal neoplasms. Trans. Ophthal. Soc. U.K., Vol. XLVIII, p. 107, 1928.

(1) Treacher Collins, in a paper read to the Ophthalmological Society of the United Kingdom at the Annual Congress in 1928, discussed the natural history of retinal neoplasms under the following headings :-

(1) Are cases of retinal glioma on the increase?

An analysis of cases suffering from glioma at Moorfields Hospital between the years 1871-1924 shows that this disease is not increasing, for during the first 26 years of this period (between 1871 and 1897) 83 cases were examined, and during the remaining 27 years (1897-1924) 80 cases have been seen. 